\title{
Effectiveness of simple balancing training program in elderly patients with history of frequent falls
}

This article was published in the following Dove Press journal:

Clinical Interventions in Aging

4 May 201I

Number of times this article has been viewed

Vilai Kuptniratsaikul'

Rungnirand Praditsuwan ${ }^{2}$

Prasert Assantachai ${ }^{3}$

Teerada Ploypetch'

Suthipol Udompunturak ${ }^{4}$

Julaporn Pooliam ${ }^{4}$

'Department of Rehabilitation Medicine, ${ }^{2}$ Department of Medicine, ${ }^{3}$ Department of Preventive Medicine, ${ }^{4}$ Office for Research and Development, Siriraj Hospital, Mahidol University, Thailand
Correspondence: Vilai Kuptniratsaikul Department of Rehabilitation Medicine, Faculty of Medicine, Siriraj Hospital, Mahidol University, 2 Prannok Rd, Bangkok 10700, Thailand

Tel +6624197508

Fax +6624 II 48I3

Email sivkp@mahidol.ac.th
Objective: To study the effectiveness of simply-performed balancing exercises in fall prevention.

Design: Pre- and post-trial.

Setting: University hospital from January 2009 to May 2010.

Participants: Elderly with falls in the previous year.

Intervention: Simple balancing exercise was performed at home every day and was recorded in the booklet.

Measurements: New falling events and a battery of balancing abilities including the Timed Up and Go Test (TUGT), chair stand, functional reach, and Berg balance scale-short form were evaluated at baseline, 3-, 6-, 9-, and 12-month periods. Fear of falling and quality of life scores were assessed at baseline and 12-month periods.

Results: 146 subjects were recruited, 116 female (79.5\%) with a mean age of 67.1 years. At the end of the study, $49 \%$ of participants had not fallen. All of the balancing abilities were compared between frequent and infrequent fallers and were significantly improved $(P<0.001)$ except for functional reach in the frequent fall group. Most subjects $(72 \%-79 \%)$ complied well with the exercise program. However, compliance had no effect on balancing abilities. About $36.4 \%$ of participants had adverse events from exercise, of which knee pain was the top ranked. The quality of life and the fall efficacy scores increased significantly at the end of the study. Factors affecting falling were compliance with exercise (adjusted odds ratio [OR]: 2.55, 95\% confidence intervals $[\mathrm{CI}]: 1.04,6.30$ ) and a history of falling $\geq 3$ times in the previous year (adjusted OR: $3.76,95 \%$ CI: $1.18,11.98)$.

Conclusion: Performing simply-designed balancing exercises, at least 3 days per week, can increase balancing abilities, and decrease fall rates in the elderly with a history of previous falls. However, strategies to encourage elderly compliance may prevent falling.

Keywords: balancing training, exercise, fall prevention, frequent fall, elderly

\section{Introduction}

Falling is one of the most common problems in the elderly that can cause morbidity, including fracture and disability, and mortality. It may have negative effects on physical, psychological, and socioeconomic status. The incidence of falls in a population of community-dwelling older adults will increase with advancing age: Downton ${ }^{1}$ found that the incidence was $28 \%-35 \%$ in elderly aged more than 65 years, and $32 \%-42 \%$ in those aged more than 75 years. Elderly with a history of falls are at greater risk of falling again. ${ }^{2}$ Approximately $30 \%$ of falls result in an injury that requires medical attention, and approximately $10 \%$ result in a fracture. ${ }^{3}$ Fall prevention is an important strategy for reducing osteoporotic fractures. Hektoen et al estimated the cost-effectiveness of 
fall prevention, which can reduce health care costs for treating fall-related injuries, was 1.85 times higher than the cost of implementing a fall prevention program. ${ }^{4}$

There is evidence that exercise can prevent falls. ${ }^{5-8}$ Exercise is beneficial even in those aged more than 80 years. ${ }^{9}$ Petridou et al reported that exercise-alone interventions were about five times more effective in reducing recurrent falls among community-dwelling older people compared with multifactorial interventions. ${ }^{10}$ Therefore, encouraging older adults to participate in exercise should be beneficial. Among multimodal exercises, a meta-analysis of the seven Frailty and Injuries: Cooperative Studies of Intervention Techniques (FICSIT) exercise trials suggests that balance exercise may be more effective in lowering falls risk than the other exercise components. ${ }^{11}$

Models of exercise vary, including computerized feedback postural training programs; sophisticated exercise machines; and controlled group exercise in the hospital. ${ }^{12,13}$ However, older adults who are at risk usually refuse to participate in hospital-based exercise programs. ${ }^{14}$ Home-based exercises may be appropriate for such a long term condition. Therefore, we aimed to study the effectiveness of simplyperformed balancing training exercise, done at home, in reducing falls and improving balancing abilities in elderly patients who had already suffered from falls, and to follow up these effects for 1 year.

\section{Methods}

This study was conducted at Siriraj Hospital, Thailand, from January 2009 to May 2010. Following Siriraj Ethical Committee approval, we recruited elderly out-patients who had a history of falls in the previous 12 months. Our definition of fall was "an event that resulted in a person coming to rest unintentionally on the ground or other lower level, and which does not occur as a result of an intrinsic event or overwhelming hazard". ${ }^{15}$ The inclusion criteria were: elderly aged more than 50 years who fell; or those with a history of osteoporotic fracture in the previous year. Those who could not follow commands, or had a severe medical condition that prevented them from performing exercise, were excluded.

After participants signed the informed consent, demographic data including age, sex, underlying diseases, fall history, walking ability, turning, ability to go outside by oneself, and fear of fall history were recorded. Participants were evaluated for balancing abilities using a battery of tests including: Timed Up and Go test (TUGT) ${ }^{16}$ (time taken to rise from a chair, walk a $3 \mathrm{~m}$ distance, turn around, walk back and sit down); chair stand ${ }^{17}$ (time taken to rise from a chair with arms folded and sit down, repeated five times); functional reach ${ }^{18}$ (distance that participants can reach their arms forward as far as they can without losing balance); and Berg balance scale-short form (BBS-SF) ${ }^{19}$ (score ranged from 0-28, high = good balance). The BBS-SF was composed of only seven items from the Berg balance scale (BBS). ${ }^{20}$ It was proved to be psychometrically similar to the original BBS. All of the tests were conducted sequentially at baseline, and after 3 months, 6 months, 9 months, and 12 months in the exercise program. In addition, quality of life scores (SF-36) ${ }^{21}$; a specific health questionnaire assessing physical functioning; psychological functioning; social functioning and vitality; and fall efficacy scale (FES), ${ }^{22}$ a 14-activity questionnaire identifying early stages of fear of falling in active communitydwelling older people, were assessed both at baseline and after a 12-month period.

Participants were shown how to perform easy balancing exercises. They practiced the exercises until they could perform them correctly. All received brochures and a DVD reminding them how to exercise daily at home. The exercises included: strengthening exercise, emphasizing hip abductors and extensors; closed kinetic chain quadriceps exercise; marching; stepping over a bench; standing up from a chair with arms folded; and tandem walk (walking heel-to-toe in a straight line). They were asked to perform seven balance exercises, 10-20 repetitions for each, which took about 15-20 minutes per day, record the frequency of exercise or compliance in their diaries and bring these records to the researchers every visit. Participants who exercised less than 3 days per week were classified as having poor compliance, while good compliance was defined as performing exercise at least 3 days per week. In addition, the relationship between compliance with exercise and balancing abilities were analyzed. According to the classification of exercise compliance at 1-year follow up, subjects who were categorized in the good compliance group had to report good compliance at every visit; otherwise, they were classified in the poor compliance group. Moreover, new falls during the study period were also recorded prospectively in their diaries. The factors related to falls were also analyzed.

\section{Statistical analysis}

Demographic data was presented by descriptive statistics. A Chi-square test was applied to compare fall frequencies between the baseline and 1-year period by per-protocol and intention-to-treat analysis methods. Balancing abilities, quality of life scores (SF-36), and FES at baseline and 1 year after were compared by paired $t$-test. Factors associated with falls were analyzed using a Chi-square test or Fisher's exact test 
Table I Demographic data of I46 participants

\begin{tabular}{ll}
\hline Demographic data & $\mathbf{n}=\mathbf{I 4 6}$ \\
\hline Age (years) & $67.1 \pm 8.4$ \\
Body mass index $\left(\mathrm{kg} / \mathrm{m}^{2}\right)$ & $25.2 \pm 4.4$ \\
Sex: female & $116(79.5 \%)$ \\
Marital status: married & $70(47.9 \%)$ \\
Underlying diseases & \\
$\quad$ Dyslipidemia & $70(47.9 \%)$ \\
Hypertension & $69(47.3 \%)$ \\
Diabetes mellitus & $23(15.8 \%)$ \\
Ischemic heart disease & $9(6.2 \%)$ \\
History of previous fracture & $18(12.8 \%)$ \\
Walking independently & $125(86.8 \%)$ \\
Able to go outside by themselves & $132(90.4 \%)$ \\
Medication use $\geq 4$ & $44(34.1 \%)$ \\
Fear of falling & $110(75.3 \%)$ \\
Swaying on turning & $87(59.6 \%)$ \\
Difficulty on turning & $49(33.6 \%)$ \\
\hline
\end{tabular}

for qualitative data. Multiple logistic regression was used to analyze the confounding factors. A $P$-value of $\leq 0.05$ was considered statistically significant. Analyses were performed using PASW statistic 18 (SPSS Inc, Chicago, IL).

\section{Results}

One hundred and forty-six elderly subjects were recruited via an advertising board in our hospital. We compared the retained and drop-out subjects by age, sex and frequency of previous fall and fracture, and found that there were no significant differences except age (66.5 \pm 8.0 and $70.0 \pm 9.2$ years in retained and drop-out groups respectively). There were 28 subjects $(19.2 \%)$ lost to follow-up due to inability to contact $(8,5.5 \%)$, unavailability $(9,6.2 \%)$, being withdrawn from the study $(8,5.5 \%)$, and only three $(2.0 \%)$ had serious medical problems (stroke, craniotomy and myocardial infarction). The craniotomy was due to a fall and the event occurred within the first month after recruitment. The patient had fallen four times in the previous year. No one died or suffered hip fractures in our study. Only $104(71.2 \%)$ could be completely followed up through 1 year.

Table 1 shows the demographic data of the 146 subjects. Most of the subjects were female $(116,79.5 \%)$ with a mean age of 67.1 years. The average BMI was $25.2 \pm 4.4 \mathrm{~kg} / \mathrm{m}^{2}$. About half of them were married. The three most frequent underlying diseases were dyslipidemia (47.9\%), hypertension (47.3\%), and diabetes mellitus (15.8\%). Thirteen percent of subjects had a history of fracture due to falls. Almost all of them could walk independently (86.8\%) and were able to go outside by themselves (90.4\%). The number of subjects who used more than four medications was 44 (34.1\%). Three-quarters (75.3\%) reported fear of falling, $59.6 \%$ had swaying on turning, and $33.6 \%$ had difficulty on turning.

Table 2 presents the number of falls in the test group at the baseline and at 1 year, compared between per-protocol (PP) and intention-to-treat (ITT) analysis methods. At baseline, all subjects had a history of at least one previous fall. At the end of the study, 51 (49\%) participants had not fallen during the study period. The number of patients who fell was decreased at the 12-month period. At baseline, 69 subjects $(47.3 \%)$ had fallen once and 77 subjects $(52.7 \%)$ had fallen twice or more. During the 12-month study period, 24 patients (23.1\%) fell once and 29 patients $(27.9 \%)$ fell twice or more. After using ITT analysis, we hypothesized that all the subjects who were lost to the study fell at least once and the frequency of falls was summated during the whole year period. The results from ITT were related to the PP method $(P<0.001)$ as presented in Table 2.

Balancing abilities including TUGT, chair stand, functional reach and Berg balance scale-short form, at baseline and 1-year follow up period, for both frequent and infrequent falls groups are shown in Table 3 . They were significantly improved except for functional reach in the frequent fall

Table 2 The number (\%) and 95\% confidence interval of subjects who fell at baseline and I2-month after recruitment (cumulative frequency), analyzed by per protocol (PP) and intention-to-treat (ITT) methods

\begin{tabular}{|c|c|c|c|c|c|c|}
\hline \multirow[t]{2}{*}{ Fall frequency } & \multicolumn{2}{|l|}{ Per protocol } & \multirow[t]{2}{*}{$P$-value } & \multicolumn{2}{|c|}{ Intention-to-treat ${ }^{\mathrm{b}}$} & \multirow[t]{2}{*}{$P$-value } \\
\hline & $\begin{array}{l}\text { Baseline } \\
(n=146)\end{array}$ & $\begin{array}{l}\text { I2-month } \\
(\mathrm{n}=104)^{\mathrm{a}}\end{array}$ & & $\begin{array}{l}\text { Baseline } \\
(n=146)\end{array}$ & $\begin{array}{l}\text { I2-month } \\
(n=146)\end{array}$ & \\
\hline Did not fall & - & $\begin{array}{l}51(49.0 \%) \\
(39.6 \%, 58.5 \%)\end{array}$ & $<0.001 *$ & - & $\begin{array}{l}51(34.9 \%) \\
(27.7 \%, 43.0 \%)\end{array}$ & $<0.001 *$ \\
\hline Fell one time & $\begin{array}{l}69(47.3 \%) \\
(39.3 \%, 55.3 \%)\end{array}$ & $\begin{array}{l}24(23.1 \%) \\
(16.0 \%, 32.0 \%)\end{array}$ & & $\begin{array}{l}69(47.3 \%) \\
(39.3 \%, 55.3 \%)\end{array}$ & $\begin{array}{l}28(19.2 \%) \\
(13.6 \%, 26.3 \%)\end{array}$ & \\
\hline Fell $\geq$ two times & $\begin{array}{l}77(52.7 \%) \\
(44.7 \%, 60.7 \%)\end{array}$ & $\begin{array}{l}29(27.9 \%) \\
(20.2 \%, 37.2 \%)\end{array}$ & & $\begin{array}{l}77(52.7 \%) \\
(44.7 \%, 60.7 \%)\end{array}$ & $\begin{array}{l}67(45.9 \%) \\
(38.0 \%, 54.0 \%)\end{array}$ & \\
\hline
\end{tabular}

Notes: ${ }^{a}$ Only 104 subjects could be completely followed up every visit; at a level of 0.05 . 
Table 3 Mean (SD) of the balancing abilities at baseline and I2-month follow up period compared between infrequent fall and frequent fall groups $(\mathrm{N}=\mathrm{I} / 8)$

\begin{tabular}{|c|c|c|c|c|c|c|c|c|}
\hline \multirow[t]{2}{*}{ Balancing abilities } & \multicolumn{2}{|c|}{$\begin{array}{l}\text { Infrequent falls }{ }^{a} \\
(n=54)\end{array}$} & \multirow[t]{2}{*}{$P$-value } & \multicolumn{2}{|c|}{$\begin{array}{l}\text { Frequent falls } \\
(n=64)\end{array}$} & \multirow[t]{2}{*}{$P$-value } & \multirow[t]{2}{*}{$\begin{array}{l}\text { Mean difference } \\
(95 \% \mathrm{Cl})\end{array}$} & \multirow[t]{2}{*}{$P$-value } \\
\hline & Baseline & I2-month & & Baseline & I2-month & & & \\
\hline TUGT (s) & II.6 (4.I) & $8.3(2.0)$ & $<0.001 *$ & II.6 (4.2) & $9.2(5.9)$ & $<0.001 *$ & $-0.88(-2.24,0.49)$ & 0.21 \\
\hline Chair stand(s) & $14.5(4.5)$ & $9.5(1.8)$ & $<0.00 I^{*}$ & I5.2(5.0) & $10.1(2.7)$ & $<0.00 I^{*}$ & $-0.45(-1.17,0.27)$ & 0.22 \\
\hline Functional reach $(\mathrm{cm})$ & $25.9(5.5)$ & $27.8(6.5)$ & $0.015^{*}$ & $26.5(5.2)$ & $27.9(6.3)$ & 0.055 & $0.35(-1.59,2.28)$ & 0.72 \\
\hline Berg balance score & $24.6(2.7)$ & $25.5(3.1)$ & $0.03 I^{*}$ & $24.5(3.8)$ & $25.5(3.8)$ & $0.004 *$ & $-0.04(-0.98,0.90)$ & 0.93 \\
\hline
\end{tabular}

Notes: anfrequent fall means fall 0-I time; 'Frequent falls means fall $\geq$ two times; 'Mean difference between infrequent and frequent falls at I2-month adjusted for baseline values using regression analysis; ${ }^{*}$ Statistical significance at a level of 0.05 .

Abbreviation: TUGT, timed up and go test.

group. The mean difference between infrequent and frequent falls at 12-month was not statistically significant between groups (using regression analysis). Compliance was good (72\%-79\%) with most subjects (Table 4). According to Figure 1, compliance has no effect on balancing abilities.

At the end of the study, the quality of life score increased significantly in 8 domains (Figure 2). The fall efficacy score (FES) also increased significantly (116.6 \pm 26.4 versus $121.7 \pm 23.1$ at baseline and 12-month respectively). Regarding the adverse events (AE) of exercise, 48 out of 132 participants (36.4\%) had an AE, of which knee pain was the top ranked $(20,15.2 \%)$, followed by calf pain and hip pain (6, $4.5 \%$ and $5,3.8 \%$, respectively).

The factors affecting frequency of fall including age, sex, underlying diseases, fear of falling, history of falls, compliance with exercise, medication use, difficulty on turning, swaying on turning, ability to walk, and ability to go outside were analyzed. However, only compliance with the exercise program (adjusted odds ratio [OR]: 2.55, 95\% confidence interval $[\mathrm{CI}]: 1.04,6.30)$ and a history of fall $\geq$ three times in the previous year (adjusted OR: 3.76, 95\% CI: 1.18, 11.98) were related to falls (Table 5).

\section{Discussion}

Our study showed that simply-designed balancing exercises used by the elderly who have a history of frequent falls can decrease fall rate, and significantly increase balancing abilities including TUGT, chair stand, functional reach and Berg balance scores. The improved outcomes may be due to the encouragement of the elderly to be aware of falls and to perform regular exercise at home. However, all the balancing abilities were secondary outcomes. Our primary outcome, number of falls, was significantly reduced after intervention.

There are many systematic reviews concerning fall prevention in the elderly. ${ }^{23-26}$ An analysis by Gillespie et al of 55,303 participants revealed that multiple-component group exercise could reduce the rate of falls in older people living in the community (rate ratio: $0.78,95 \%$ CI: $0.71-0.86$ ). ${ }^{8}$ Another review also confirmed that balancing exercises can reduce the rate of falling (rate ratio: $0.83,95 \% \mathrm{CI}$ : $0.75-0.91) .{ }^{27}$ It is beneficial even in those older than 80 years. ${ }^{9,28}$ However, the type of exercise that the elderly could accept and comply well with was still questionable. Therefore, we designed a simple balancing exercise that was easily done at home, with less adverse events, and which was appropriate for the elderly.

There are many factors relating to falls including age, muscle power, impaired balance, use of psychoactive drugs, poor vision and degenerative joint disease., 29 Our study revealed that one of the factors affecting fall rate was a history of previous falls. This was in accordance with other studies which reported that patients with a history of falls during the previous year showed an increased risk of falls..$^{30-32}$ Those who had repeated falls will have an increased risk of trauma and fracture as well. Therefore, strategies to prevent falls, including reviewing medications, correction of environment,

Table 4 Compliance with exercise during 3-month, 6-month, 9-month and I2-month follow up period

\begin{tabular}{|c|c|c|c|c|c|}
\hline Compliance $^{a}$ & $\begin{array}{l}\text { 3-month } \\
(n=132)\end{array}$ & $\begin{array}{l}\text { 6-month } \\
(n=12 I)\end{array}$ & $\begin{array}{l}\text { 9-month } \\
(n=I I I)\end{array}$ & $\begin{array}{l}\text { I2-month } \\
(n=|| 8)\end{array}$ & $\begin{array}{l}\text { Completely } \mathrm{F} / \mathrm{U} \\
(\mathrm{n}=104)^{\mathrm{b}}\end{array}$ \\
\hline Good & $95(72.0 \%)$ & $94(77.7 \%)$ & 86 (77.5\%) & $93(78.8 \%)$ & $60(57.7 \%)$ \\
\hline Poor & 37 (28.0\%) & 27 (22.3\%) & 25 (22.5\%) & $25(21.2 \%)$ & 44 (42.3\%) \\
\hline
\end{tabular}

Notes: ${ }^{a}$ Compliance: good means exercise at least three days per week, poor means exercise less than three days per week; ${ }^{\text {PPatients }}$ who could be completely followed up every visit.

Abbreviation: $F / U$, followed up. 

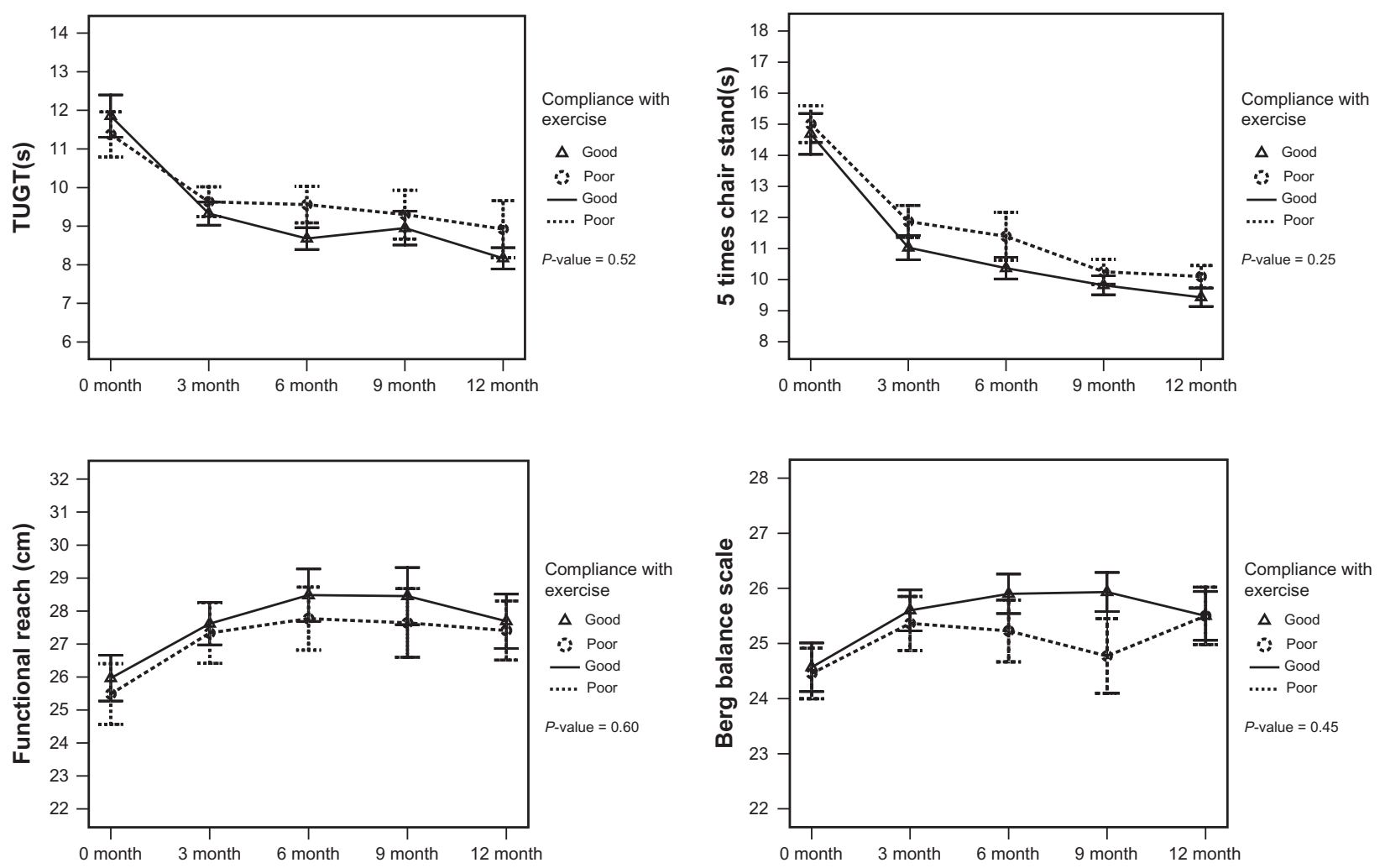

Figure I Balancing abilities including timed up and go test, chair stand, functional reach, and Berg balance scale based on compliance with exercise.

improvement of strength, and regular balance training, should be encouraged in the elderly.

Compliance is another factor affecting fall rate in our study. Most subjects performed exercise regularly at least 3 days per week. However, we could not demonstrate that compliance had any effect on balancing abilities. The reasons may be because 1) the number of subjects in each group was insufficient (60 in good compliance and

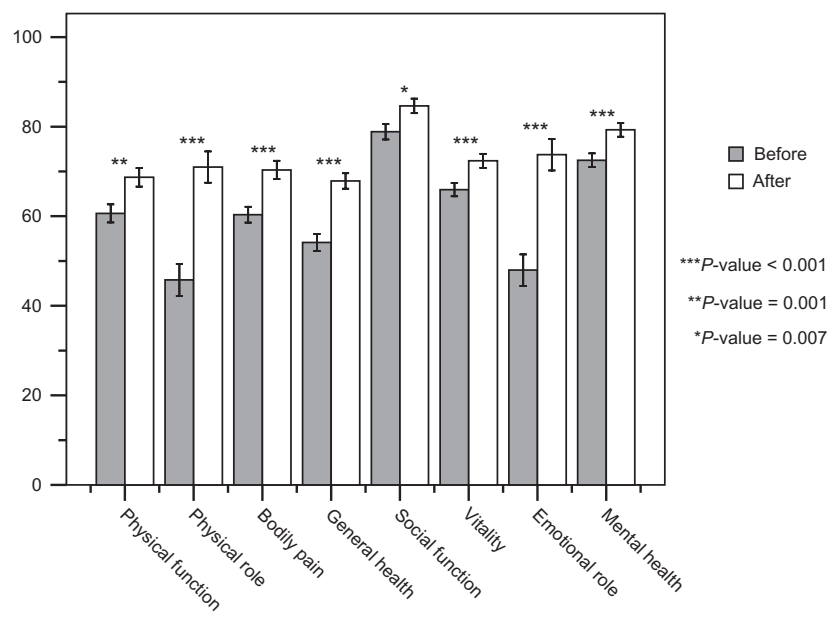

Figure 2 Quality of life score (SF-36) of 104 participants compared between baseline and I-year after.
44 in poor compliance groups) to demonstrate significant changes in each groups' balancing abilities, 2) most of our participants were "young-old" (mean age was $67.1 \pm 8.4$ years, and 88 patients $(60.3 \%)$ were less than 70 years), so their balance would be better than in participants in other studies where the mean age was higher, 3) difficulty experienced by elderly patients in recording the frequency of exercise, 4) these balancing abilities may not be sensitive enough to represent true balance, 5) the final classification group of compliance with exercise may be our limitation because to be classified in the good compliance group, subjects had to perform well at every visit; otherwise, they were classified in the poor compliance group. However, encouraging the elderly to participate in exercise regularly should be emphasized because this method was an effective strategy. Moreover, prevention of falls using exercise is cost-efficient, so it can be implemented in countries with fewer resources. ${ }^{10}$

This simply-designed exercise also affects quality of life (QoL) in both physical and mental health dimensions. The results in this study showed the benefits of balancing exercise in decreased fall rates, and increased QoL. Our study was in line to that of Lin et al, ${ }^{33}$ who reported that QoL scores in an exercise group of elderly with recent falls 
Table 5 Crude odds and adjusted odds of the factors relating to fall frequency $(\mathrm{N}=104)$

\begin{tabular}{|c|c|c|c|c|}
\hline Factors & $\begin{array}{l}\text { Infrequent falls } \\
(\mathrm{n}=75)\end{array}$ & $\begin{array}{l}\text { Frequent falls } \\
(n=29)\end{array}$ & $\begin{array}{l}\text { Crude odds ratio }^{a} \\
(95 \% \mathrm{Cl})\end{array}$ & $\begin{array}{l}\text { Adjusted odds }{ }^{b} \\
(95 \% \mathrm{Cl})\end{array}$ \\
\hline \multicolumn{5}{|l|}{ Age } \\
\hline$<75$ & $66(88.0 \%)$ & $23(79.3 \%)$ & 1.0 & \multirow[t]{2}{*}{-} \\
\hline$\geq 75$ & $9(12.0 \%)$ & $6(20.7 \%)$ & $1.91(0.61,5.96)$ & \\
\hline \multicolumn{5}{|l|}{ Sex } \\
\hline Male & $16(21.3 \%)$ & $8(27.6 \%)$ & 1.0 & \multirow[t]{2}{*}{-} \\
\hline Female & 59 (78.7\%) & $2 \mathrm{I}(72.4 \%)$ & $0.71(0.27,1.90)$ & \\
\hline \multicolumn{5}{|l|}{ Underlying diseases } \\
\hline $0-1$ & 4 I (54.7\%) & $14(48.3 \%)$ & 1.0 & \multirow[t]{2}{*}{-} \\
\hline$\geq 2$ & $34(45.3 \%)$ & $15(51.7 \%)$ & $1.29(0.55,3.05)$ & \\
\hline \multicolumn{5}{|l|}{ Fear of fall } \\
\hline No & $15(20.0 \%)$ & $10(34.5 \%)$ & 1.0 & \multirow[t]{2}{*}{-} \\
\hline Yes & $60(80.0 \%)$ & $19(65.5 \%)$ & $0.48(0.18,1.23)$ & \\
\hline \multicolumn{5}{|l|}{ Previous fall } \\
\hline$<3$ times & $68(90.7 \%)$ & $2 \mathrm{I}(72.4 \%)$ & 1.0 & 1.00 \\
\hline$\geq 3$ times & 7 (9.3\%) & $8(27.6 \%)$ & $3.70(1.20,11.41)^{*}$ & $3.76(1.18,11.98)^{* *}$ \\
\hline \multicolumn{5}{|c|}{ Compliance with exercise } \\
\hline Good & $48(64.0 \%)$ & 12 (4I.4\%) & 1.0 & 1.00 \\
\hline Poor & 27 (36.0\%) & $17(58.6 \%)$ & $2.52(1.05,6.05)^{*}$ & $2.55(1.04,6.30)^{* * * k}$ \\
\hline \multicolumn{5}{|l|}{ Medication use } \\
\hline $0-3$ & $50(66.7 \%)$ & $23(79.3 \%)$ & 1.0 & \multirow[t]{2}{*}{-} \\
\hline$\geq 4$ & $25(33.3 \%)$ & $6(20.7 \%)$ & $0.52(0.19,1.45)$ & \\
\hline \multicolumn{5}{|l|}{ Difficulty on turning } \\
\hline No & 47 (62.7\%) & 21 (72.4\%) & 1.0 & \multirow[t]{2}{*}{-} \\
\hline Yes & $28(37.3 \%)$ & $8(27.6 \%)$ & $0.64(0.25,1.64)$ & \\
\hline \multicolumn{5}{|l|}{ Swaying on turning } \\
\hline No & $28(37.3 \%)$ & 15 (5I.7\%) & 1.0 & \multirow[t]{2}{*}{-} \\
\hline Yes & 47 (62.7\%) & 14 (48.3\%) & $0.56(0.23,1.32)$ & \\
\hline \multicolumn{5}{|l|}{ Walking ability } \\
\hline Independent & 67 (89.3\%) & 27 (93.1\%) & 1.0 & \multirow[t]{2}{*}{-} \\
\hline With aids & 8 (10.7\%) & $2(6.9 \%)$ & $0.60(0.12,3.11)$ & \\
\hline \multicolumn{5}{|l|}{ Going outside } \\
\hline Independent & 68 (90.7\%) & $28(96.6 \%)$ & 1.0 & \multirow[t]{2}{*}{-} \\
\hline Need assistance & $7(9.3 \%)$ & I (3.4\%) & $0.35(0.04,2.95)$ & \\
\hline
\end{tabular}

Notes: ${ }^{a}$ Chi-square test, Fisher's exact test for qualitative data; ${ }^{b}$ Multiple logistic regression analysis; $*$ Statistical significance at a level of $0.05 ; * * P$-value $=0.03 ; * * * P$-value $=0.04$. Abbreviation: $\mathrm{Cl}$, confidence interval.

was greater than in those in an education group or a home safety assessment and modification group. Therefore, we can conclude that exercise improves both balance and quality of life. Encouraging the elderly to exercise regularly is an effective way to prevent falls, and should be emphasized in medical practices.

There are some limitations in our study. 1) We had no control group. We only compared pre- and post-intervention in the frequent faller group, so our results were not suitable for a randomized controlled trial (RCT) design. We did not recruit non-fallers because our objective was to study the efficacy of simple balance exercise in frequent fallers. 2) The number of participants who could be completely followed up was only 104 from 146 (71.2\%). In addition, the 28 subjects who were lost to follow up were older than the retained subjects. This may be due to the need to make multiple visits to the clinic during the study period. 3) The record of compliance of exercise in elderly patients is rather difficult to validate.

\section{Conclusion}

A simply-designed balancing exercise program, performed at least 3 days per week, can increase balancing abilities, and decrease fall rates in the elderly with previous falls. However, strategies to encourage elderly compliance may prevent falling.

\section{Acknowledgments}

This study was supported by a grant from The National Research Council of Thailand. We would like to thank Ms P Lymampai, Mrs A Leurcharusmee, Mrs K Sungkarak, and Mrs S Salika for their cooperation. 


\section{Disclosure}

The authors report no conflicts of interest in this work.

\section{References}

1. Downton JH. Falls. In: Tallis R, Fillit H, Brocklehurst JC, editors. Geriatric Medicine and Gerontology, 5th ed. Edinburgh, Scotland: Churchill Livingstone; 1998:1359-1370.

2. Formiga F, Navarro M, Duaso E, et al. Factors associated with hip fracture-related falls among patients with a history of recurrent falling. Bone. 2008;43:941-944.

3. Berry SD, Miller RR. Falls: epidemiology, pathophysiology, and relationship to fracture. Curr Osteoporos Rep. 2008;6:149-154.

4. Hektoen LF, Aas E, Lurås H. Cost-effectiveness in fall prevention for older women. Scand J Public Health. 2009;37:584-589.

5. Kannus P, Uusi-Rasi K, Palvanen M, Parkkari J. Non-pharmacological means to prevent fractures among older adults. Ann Med. 2005;37: 303-310.

6. Baker MK, Atlantis E, Fiatarone Singh MA. Multi-modal exercise programs for older adults. Age Ageing. 2007;36:375-381.

7. Skelton DA, Beyer N. Exercise and injury prevention in older people. Scand J Med Sci Sports. 2003;13:77-85.

8. Gillespie LD, Robertson MC, Gillespie WJ, et al. Interventions for preventing falls in older people living in the community. Cochrane Database Syst Rev. 2009;2:CD007146.

9. Davis JC, Robertson MC, Ashe MC, Liu-Ambrose T, Khan KM, Marra CA. Does a home based strength and balance programme in people aged $\geq 80$ years provide the best value for money to prevent falls? A systematic review of economic analyses of falls prevention interventions. Br J Sports Med. 2010;44:80-89.

10. Petridou ET, Manti EG, Ntinapogias AG, Negri E, Szczerbinska K. What works better for community-dwelling older people at risk to fall?: a meta-analysis of multifactorial versus physical exercise-alone interventions. J Aging Health. 2009;21:713-729.

11. Province MA, Hadley EC, Hornbrook MC, et al. The effects of exercise on falls in elderly patients. A preplanned meta-analysis of the FICSIT Trials. Frailty and Injuries: Cooperative Studies of Intervention Techniques. JAMA. 1995;273:1341-1347.

12. Lajoie Y. Effect of computerized feedback postural training on posture and attentional demands in older adults. Aging Clin Exp Res. 2004;16: 363-368.

13. Judge JO, Lindsey C, Underwood M, Winsemius D. Balance improvements in older women: effects of exercise training. Phys Ther. 1993;73: 254-262.

14. Barr R, Macdonald H, Stewart A, et al. Association between vitamin D receptor gene polymorphisms, falls, balance and muscle power: results from two independent studies (APOSS and OPUS). Osteoporos Int. 2010;21:457-466.

15. Clark RD, Lord SR, Webster IW. Clinical parameters associated with falls in an elderly population. Gerontology. 1993;39:117-123.

16. Podsiadlo D, Richardson S. The timed "Up and Go": a test of basic functional mobility for frail elderly persons. JAm Geriatr Soc. 1991;39: $142-148$.
17. Guralnik JM, Simonsick EM, Ferrucci L, et al. A short physical performance battery assessing lower extremity function: association with self-reported disability and prediction of mortality and nursing home admission. J Gerontol. 1994;49:M85-M94.

18. Duncan PW, Weiner DK, Chandler J, Studenski S. Functional reach: a new clinical measure of balance. J Gerontol. 1990;45:M192-M197.

19. Chou CY, Chien CW, Hsueh IP, et al. Developing a short form of the Berg Balance Scale for people with stroke. Phys Ther. 2006;86: 195-204.

20. Berg K, Wood-Dauphinee S, Williams JI, Gayton D. Measuring balance in the elderly: preliminary development of an instrument. Physiother Can. 1989;41:304-311.

21. Kongsakon R, Silpakit C. Thai version of the medical outcome study 36 items short form health survey: an instrument for measuring clinical results in mental disorder patients. Rama Med J. 2000;23:8-19.

22. Hill KD, Schwarz JA, Kalogeropoulos AJ, Gibson SJ. Fear of falling revisited. Arch Phys Med Rehabil. 1996;77:1025-1029.

23. Gillespie LD, Gillespie WJ, Cumming R, Lamb SE, Rowe BH. Interventions for preventing falls in the elderly. Cochrane Database Syst Rev. 2000;2:CD000340.

24. Gillespie LD, Gillespie WJ, Robertson MC, Lamb SE, Cumming RG, Rowe BH. Interventions for preventing falls in elderly people. Cochrane Database Syst Rev. 2001;3:CD000340.

25. Gillespie LD, Gillespie WJ, Robertson MC, Lamb SE, Cumming RG, Rowe BH. Interventions for preventing falls in elderly people. Cochrane Database Syst Rev. 2003;4:CD000340.

26. Howe TE, Rochester L, Jackson A, Banks PM, Blair VA. Exercise for improving balance in older people. Cochrane Database Syst Rev. 2007;4:CD004963.

27. Sherrington C, Whitney JC, Lord SR, Herbert RD, Cumming RG, Close JC. Effective exercise for the prevention of falls: a systematic review and meta-analysis. J Am Geriatr Soc. 2008;56:2234-2243.

28. Robertson MC, Campbell AJ, Gardner MM, Devlin N. Preventing injuries in older people by preventing falls: a meta-analysis of individual-level data. J Am Geriatr Soc. 2002;50:905-911.

29. Jung YM, Shin DS, Chung KS, Lee SE. Health status and fall-related factors among older Korean women: implications for nurses. $J$ Gerontol Nurs. 2007;33:12-20.

30. Nevitt MC, Cummings SR, Kidd S, Black D. Risk factors for recurrent nonsyncopal falls. A prospective study. JAMA. 1989;261:2663-2668.

31. Clough-Gorr KM, Erpen T, Gillmann G, et al. Preclinical disability as a risk factor for falls in community-dwelling older adults. J Gerontol A Biol Sci Med Sci. 2008;63:314-320.

32. Stalenhoef PA, Diederiks JP, Knottnerus JA, Kester AD, Crebolder HF. A risk model for the prediction of recurrent falls in community-dwelling elderly: a prospective cohort study. J Clin Epidemiol. 2002;55: 1088-1094.

33. Lin MR, Wolf SL, Hwang HF, Gong SY, Chen CY. A randomized, controlled trial of fall prevention programs and quality of life in older fallers. J Am Geriatr Soc. 2007;55:499-506.
Clinical Interventions in Aging

\section{Publish your work in this journal}

Clinical Interventions in Aging is an international, peer-reviewed journal focusing on evidence-based reports on the value or lack thereof of treatments intended to prevent or delay the onset of maladaptive correlates of aging in human beings. This journal is indexed on PubMed Central, MedLine, the American Chemical Society's 'Chemical Abstracts Ser-

\section{Dovepress}

vice' (CAS), Scopus and the Elsevier Bibliographic databases. The manuscript management system is completely online and includes a very quick and fair peer-review system, which is all easy to use. Visit http://www.dovepress.com/testimonials.php to read real quotes from published authors. 